\title{
Pain management in living related adult donor hepatectomy: feasibility of an evidence-based protocol in 100 consecutive donors
}

\author{
Guillaume Dewe ${ }^{1}$, Arnaud Steyaert ${ }^{1}$, Marc De Kock ${ }^{2}$, Fernande Lois $^{3}$, Raymond Reding $^{4}$ and Patrice Forget ${ }^{5^{*}}$
}

\begin{abstract}
Objective: Living donor hepatectomy (LDH) has important consequences in terms of acute and chronic pain. We proposed an anesthetic protocol based on the best currently available evidence. We report the results of this protocol's application.

Results: We performed a retrospective descriptive study of 100 consecutive donors undergoing LDH. The protocol included standardized information provided by the anesthetist, pharmacological anxiolysis and preventive analgesia. Specifically, pregabalin premedication (opioid-free) intravenous anesthesia (with clonidine, ketamine, magnesium sulphate and ketorolac) and epidural analgesia were proposed. Postoperative follow-up was conducted by the Postoperative Pain Service. This analysis included 100 patients (53 women, 47 men, median age 32.7 years old [28.4-37.3]), operated by xypho-umbilical laparotomy. All elements of our anesthetic protocol were applied in over $75 \%$ of patients, except for the preoperative consultation with a senior anesthesiologist (55\%). The median number of applied item was 7 [interquartile range, IQR 5-7]. Median postoperative pain scores were, at rest and at mobilization respectively 3 [IQR 2-4] and 6 [IQR 4.5-7] on day 1; 2 [IQR 1-3] and 5 [IQR 3-6] on day 2; and 2 [IQR 0-3] and 4 [IQR 3-5] on day 3. In conclusion, LDH leads to severe acute pain. Despite the proposal of a multimodal evidence-based protocol, its applicancy was not uniform and the pain scores remained relatively high.
\end{abstract}

Keywords: Pain management, Living related adult donor hepatectomy

\section{Introduction}

Living donor hepatectomy (LDH) for related pediatric liver transplantation is often associated with significant acute and chronic postoperative pain [1-3]. Pain is undesirable and often underestimated in its multi-factorial dimensions. Consequences of pain and the treatment of pain may be detrimental to postoperative outcome [4] and are potentially preventable [4-6].

In 2012, Bonnet et al. [3] audited postoperative pain after this surgery in our institution. The authors

\footnotetext{
*Correspondence: forgetpatrice@yahoo.fr

${ }^{5}$ Department of Anesthesiology and Perioperative Medicine, Vrije

Universiteit Brussel (VUB), Universitair Ziekenhuis Brussel (UZ Brussel),

Laarbeeklaan 101, 1090 Brussels, Belgium

Full list of author information is available at the end of the article
}

observed, on the 1 st day, that $11 \%$ and $37 \%$ of the patients reported severe postoperative pain (i.e. a score of more than 6 out of 10 on an 11-points numeric rating scale 1), respectively at rest and at movement. Additionally, the patients experiencing persistent pain after surgery presented higher pain scores than the other, highlighting the need for better acute pain management.

Following these results, we aimed to improve the quality of postoperative pain management with an evidence-based protocol. Here, we describe this protocol, systematically assess the level of evidence for each intervention, and report feasibility (i.e. acceptance) in hundred consecutive donors. 


\section{Main text}

After ethics committee approval (Number 017/02JAN/003), Chairperson: Jean-Marie Maloteaux), we performed a retrospective study of 100 consecutive donors operated between June 2010 and the February 2014 for LDH. Written informed consent was waived by the ethics committee regarding the retrospective nature of the study. Criteria for inclusion in the liver donation program at our institution are summarized in Table 1. For each donor, we retrieved demographic and surgical characteristics, perioperative anesthetic and analgesic regimen, pain scores, clinical and biological (white blood/red cell counts, platelets, C-reactive protein, liver and renal function, at day +1 and +5 ) follow-up, length of stay, postoperative complications and residual pain 2 months after the surgery.

\section{Procedures}

The perioperative anesthetic and analgesic protocol was based on the most recent and highest level of evidence with the Oxford Center for Evidence-Based Medicine (EBM). The first level of evidence (LoE 1) applies to an intervention approved by meta-analysis. Those approved by Randomized Controlled Trials are considered LoE 2 . LoE 3 is for non-randomized controlled trials, LoE 4 for other studies and LoE 5 for mechanism-based reasoning. In the following sections, we detail the LoE for each part of the protocol $[7,8]$.

\section{Preoperative phase}

Preoperative information is given by an anesthesiologist (PF, with a translator if needed) and includes a patientoriented description of the perioperative phases, procedure, (un)anticipated events, pain expectations and treatment, physical and psychological consequences (including on a short and long-term) (LoE 2) [9].

\section{Table 1 Criteria for inclusion for living liver donation}

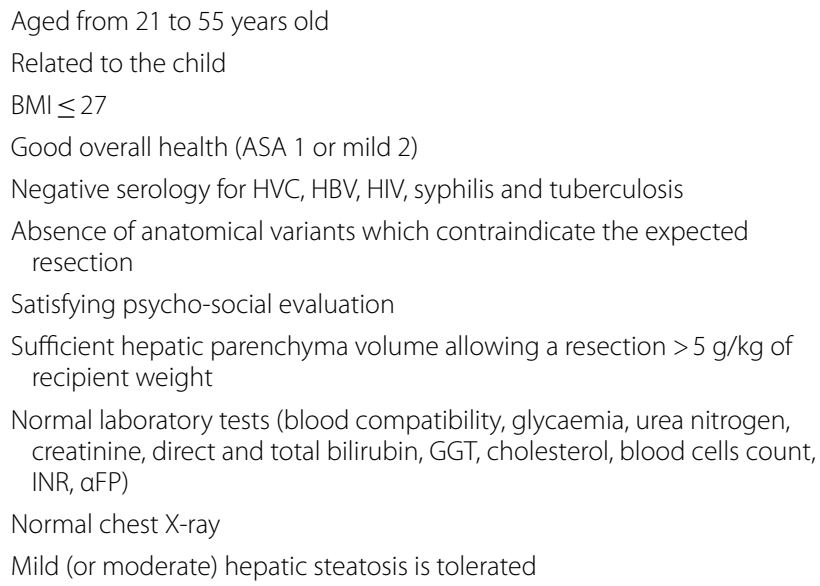

Pregabalin, as an $\alpha-2-\delta$ subunit antagonist voltagegated $\mathrm{Ca}^{2+}$ channels, has shown benefits in terms of anxiolysis (LoE 1), chronic pain (LoE 1), reduction of opioid consumption (LoE 1), improving postoperative analgesia (LoE 2), reduction of postoperative hyperalgesia (LoE 2) and prevention of chronic post-surgical pain (LoE 1) [1013]. Timing of administration is important, as it takes $6 \mathrm{~h}$ after oral administration to reach cerebrospinal fluid levels associated with decreased central nervous system sensitization [14]. To reduce preoperative anxiety (which is not limited to the day of surgery) and sleep disturbances $[15,16]$, and to obtain stable drug concentrations (i.e. after at least 5 half-life, 24-48 h $[17,18]$ ), patients received $150 \mathrm{mg}$ twice a day for 5 days before surgery (LoE 2).

Additionally, on the morning of surgery, as an anxiolytic premedication and to anticipate postoperative pain and emergence agitation, patients receive $150 \mathrm{mcg}$ of oral clonidine (LoE 1) [19].

\section{Intraoperative phase}

To decrease postoperative pain, analgesic consumption without delaying recovery, intravenous clonidine (an $\alpha 2$-agonist) is added during the induction of general anesthesia, up to $4 \mathrm{mcg} / \mathrm{kg}$ [20] (LoE 1). With its unique vasoactive properties, clonidine has the significant advantage of decreasing portal and vena cava pressure, useful in the context of hepatic surgery. It also improves hemodynamic stability and permits opioid-free anesthesia. While adverse effects are well known (hypotension and bradycardia), they have not been associated with any significant sequel, confirming its safety profile [21-23] (LoE 1).

Due to the small number of pediatric liver transplantation centers in the world, most of these donors come from abroad and do not speak either French, English or Dutch. Because of this, and regarding the living donor condition (i.e. typically at risk of high levels of anxiety), and depending on the preference of the patient, we propose an inhalatory induction (sevoflurane), before a large venous catheter placement (LoE 5).

After the induction, the anesthesia is maintained with a continuous infusion of propofol, guided by an electroencephalographic monitoring (Neurowave Systems inc). Propofol lowers the risk of postoperative nausea and vomiting $[24,25]$ ( $\operatorname{LoE} 1)$. Moreover, there may be additional arguments for its use in the context of liver transplantation, where inflammation and ischemia-reperfusion injuries are of potential concern. Propofol has shown anti-inflammatory effects [26-30] and may also reduce acute postoperative pain scores [31] (LoE 3).

Opioids are known to cause hyperalgesia [32, 33] and high intraoperative doses are associated with higher 
postoperative pain level [32] and morphine consumption $[34,35]$ (LoE 2). Opioid-free anesthesia is a strategy that, when part of a multimodal analgesia regimen [36], suppresses the risk of intraoperative opioid-induced hyperalgesia and decreases the risk of postoperative nausea and vomiting [37] (LoE 2).

Thoracic epidural is the most effective analgesic [3840] and anti-hyperalgesic technique [40, 41] after major abdominal surgery (LoE 1). It allows opioid-sparing, lowers the incidence of pruritus and improves gut motility (LoE 1). It may decrease the incidence of chronic postoperative pain [40] (LoE 2) and possibly even mortality/ morbidity [42-46] (LoE 1). Neuraxial blockade may thus improve recovery [47]. The associated vasodilatation may reduce intraoperative blood losses. Side effects include failure, dural puncture, epidural abscess and hematoma. We systematically propose thoracic epidural analgesia to the donor, after complete information. The epidural catheter is placed using a loss-of-resistance technique, in lateral decubitus position, after the induction of the anesthesia. Levobupivacaine associated to clonidine (respectively a bolus $5 \mathrm{~mL} 0.5 \%$ and $1 \mathrm{mcg} / \mathrm{kg}$ is used, followed by a continuous infusion of $5 \mathrm{~mL} / \mathrm{h}$ of levobupivacaine $0.25 \%$ ). In case of refusal (or failure) of the epidural, an intraoperative continuous intravenous infusion of lidocaine can be proposed $(2 \mathrm{mg} / \mathrm{kg} / \mathrm{h})$, associated with a postoperative patient-controlled morphine infusion [48, 49] (LoE 1).

Ketamine is an anti-pro-inflammatory drug [50] and low "anti-hyperalgesic" doses permit opioid-sparing [33, 51-53] (LoE 1), decrease hyperalgesia [32, 53] (LoE 1) and possibly the risk of postoperative chronic pain (LoE 2) $[10,54]$. We systematically administer intravenous ketamine (bolus dose of $0.5 \mathrm{mg} / \mathrm{kg}$ at induction, followed by an intraoperative infusion of $0.25 \mathrm{mg} / \mathrm{kg} / \mathrm{h}$ until $30 \mathrm{~min}$ before awakening).

Perioperative intravenous infusion of magnesium reduces postoperative pain, morphine consumption and shivering $[55,56](\operatorname{LoE} 1)$. Our patients routinely receive a loading dose of magnesium sulphate $(2-3 \mathrm{~g})$ at the induction of anesthesia.

Administration of ketorolac, a non-steroidal antiinflammatory drug, reduces postoperative pain and analgesic use [57-61] (LoE 1) and is not associated with an increased bleeding risk [62] (LoE 2). Unless contraindicated, our protocol includes an intraoperative dose ketorolac $(0.5 \mathrm{mg} / \mathrm{kg}$, maximum of $30 \mathrm{mg})$.

A gastric tube, placed after anesthesia induction, is removed before awakening (LoE 1) [63-65].

\section{Postoperative phase}

All patients are extubated at the end of the surgery and stay $24 \mathrm{~h}$ in the intensive care unit.
Our postoperative analgesia regimen includes an epidural (typically levobupivacaine $0.125 \%$, clonidine $0.75-$ $1.5 \mathrm{mcg} / \mathrm{mL}$, sufentanil $0.1 \mathrm{mg} / \mathrm{mL} ; 5 \mathrm{~mL} / \mathrm{h}$, bolus $5 \mathrm{~mL}$, lockout $50 \mathrm{~min}$ ) or intravenous (morphine, bolus $1.4 \mathrm{mg}$, lockout $7 \mathrm{~min}, 30 \mathrm{mg} \max$ per $4 \mathrm{~h}$ for men and bolus $1 \mathrm{mg}$, lockout $5 \mathrm{~min}, 25 \mathrm{mg}$ max per $4 \mathrm{~h}$ for women) patient-controlled infusion. If necessary, acetaminophen low doses (up to $2 \mathrm{~g}$ a day) and ketorolac can be added.

An anesthesiologist and a nurse are dedicated to the Acute Pain Service. An on-call anesthesiologist is available 24/7 [66-69] (LoE 3). In case of ineffective epidural analgesia despite an additional bolus of local anesthetic, the technique is immediately replaced by an intravenous patient-controlled morphine infusion. Pain intensity is evaluated daily with an 11-point-numeric-scale $(0-10)$ and prospectively registered in an electronic database. Pain scores superior or equal to 4 and 7 are considered to be respectively in moderate-to-severe pain group [70] and severe pain group [71].

\section{Statistical analyses}

Data were presented as numbers (percentage) or median [interquartile-IQR 25-75]. As distributions are not normal (Shapiro-Wilk's test), statistical comparisons were made with Wilcoxon test followed by Bonferroni's correction. JMP Pro 12.0.1 statistical package (SAS Institute Inc., Cary, NC, USA) was used for all the analyses.

\section{Results}

\section{Donors}

This analysis included 100 consecutive donors (53 women, $47 \mathrm{men}$ ). The median age was 32.7 years [IQR 28.4-37.3]. Sixty-nine percent of the donors were classified as ASA 1 and 31\% as ASA 2. One donor's anesthesia protocol was missing and excluded from the analyses. For 39 others, postoperative pain scores were incomplete. Available data was considered for analysis.

Seventy percent of the donors were coming from other countries than Belgium (most of them come from Eastern Europe) and did not speak French, Flemish nor English. Nineteen were native from Belgium, 7 from the Netherlands, 1 from Luxembourg and 3 were coming from other countries but living in Belgium. For the others, the postoperative data were considered up to their departure from Belgium.

\section{Procedure}

In all patients, a midline abdominal incision was followed by the following liver resections: a left liver lobectomy for 90 donors, a left hepatectomy for 6 , a full left hepatectomy for 3 and a right hepatectomy for 1 donor. The median length of surgery was $312 \mathrm{~min}$ [IQR 279-328]. The different components of the protocol for prevention 
of pain and hyperalgesia and their rate of applications are summarized in Table 2. Nineteen donors received the entire protocol. Six patients refused the epidural

Table 2 Anesthetic and analgesic protocol, level of evidence (LoE) according to the Oxford Center for Evidence Based Medicine, and application rate in a series of hundred consecutive living related adult donor hepatectomy

\begin{tabular}{lll}
\hline & LoE & $\begin{array}{l}\text { Application } \\
\text { rate (\%) }\end{array}$ \\
\hline $\begin{array}{ll}\text { Preanesthesia consultation with dedi- } \\
\text { cated anesthetist }\end{array}$ & 1 & 55 \\
$\begin{array}{l}\text { Premedication with pregabalin } \\
\text { Total intravenous anesthesia }\end{array}$ & $1-2$ & 75 \\
Thoracic epidural analgesia & $1-2$ & 83 \\
Opioid-free anesthesia & $\mathrm{OlH} \rightarrow 1$ & 77 \\
Clonidine & & 79 \\
IV & 2 & 87 \\
$\quad$ Epidural) & & 91 \\
Ketamine & & 93 \\
Induction & 2 & 83 \\
$\quad$ Continuous infusion & & 78 \\
Ketorolac & 2 & 79 \\
Magnesium sulphate & 1 &
\end{tabular}

$\mathrm{OIH}$ opioid induced hyperalgesia but received all other items. Thirty donors had one element missing and 51 had more than one element missing. Focusing on the epidural analgesia, 8 donors refused the technique; for one other, the insertion of the epidural catheter was unsuccessful.

\section{Postoperative period}

Median postoperative pain scores were, at rest and at mobilization respectively 3 [IQR 2-4] and 6 [IQR 4.5-7] on day $1 ; 2$ [IQR $1-3$ ] and 5 [IQR 3-6] on day 2 ; and 2 [IQR 0-3] and 4 [IQR 3-5] on day 3 (Fig. 1).

Because of inefficacy of the epidural, two donors received a patient-controlled morphine infusion on the day of surgery. Five donors switched to a patient-controlled analgesia with morphine on the next day.

Per Dindo-Clavien classification [72], we counted 30 complications (16 grade 1,10 grade 2 and 5 grade 3a complications) during the follow-up (Additional file 1). Seventy-five patients did not present any early postoperative complication. Five patients presented more than one complication (a grade 1 and a grade 2 or 3a complication). Two left pneumothorax were due to the insertion of the central venous catheter whereas the third (right) might be secondary to the central venous catheter or the surgery. Median length of stay was 7 days [IQR 6-7].

Two months after the surgery, seven out of the 27 patients $(26 \%)$ reported persistent pain.

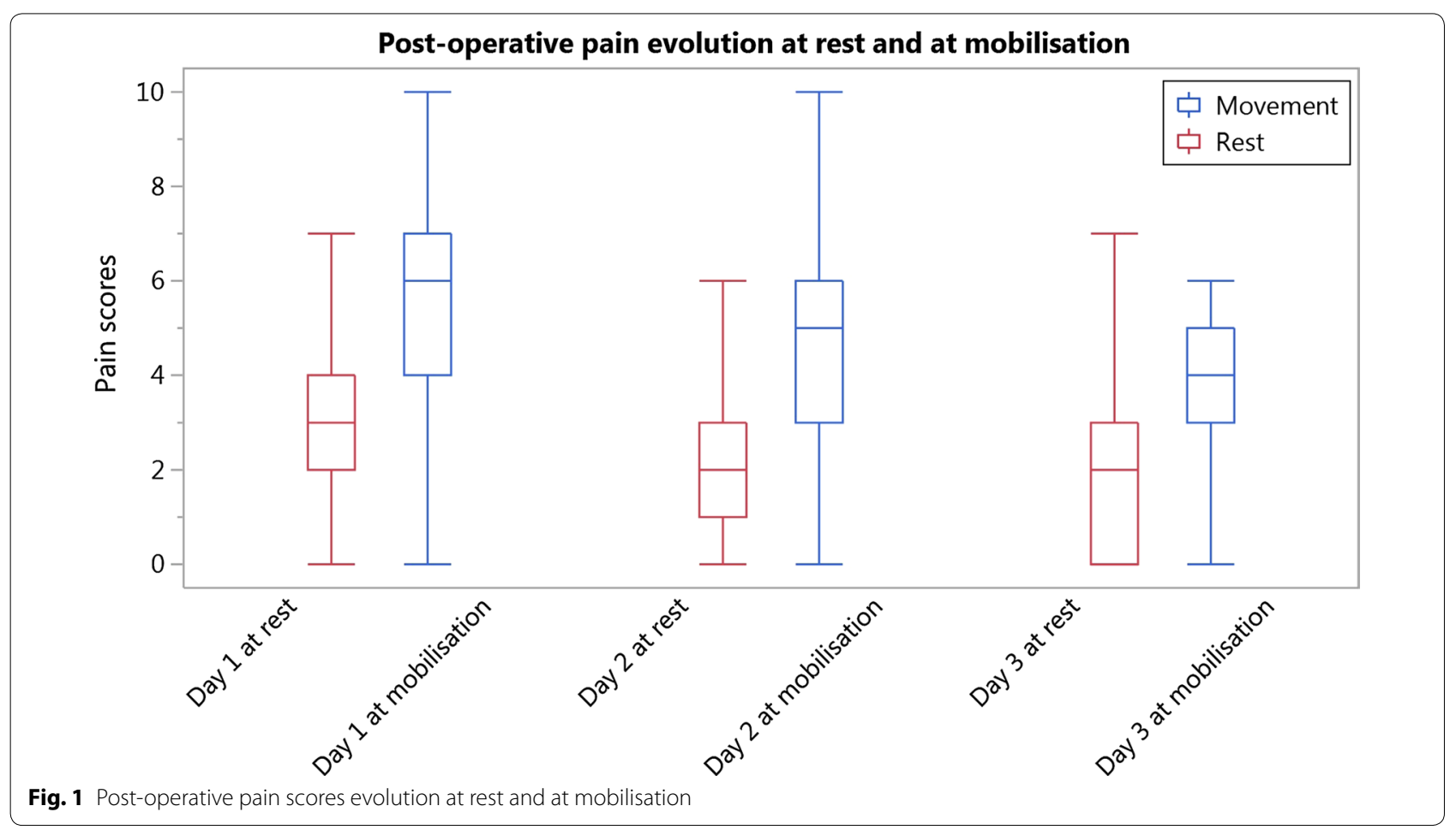


No single element of our protocol was independently associated with any of the postoperative clinical or biological outcome.

\section{Limitations}

We describe here an evidence-based protocol for pain management in living related donor undergoing hepatectomy for liver transplantation. This protocol, based on nine measures, techniques and medications is feasible and has been proposed in a series of hundred living liver donors. Our results show that, even when a protocol based on the highest level of evidence is proposed, the patients' postoperative scores are comparable to those described in the literature [2, 41]. Furthermore, the number of interventions modulating hyperalgesia precludes any statistical inference in terms of postoperative outcome. To note that psychological factors (e.g. anxiety) were difficult to follow in this context. The language barrier, for example, was an important constraint.

In total, the protocol was entirely applied in only 19 donors. There are several reasons for this. First, each anesthesiologist was free to follow this protocol. Sometimes, due to organizational constraints, the anesthesiologist in charge might not have been one of the core team. A last limitation is the fact that the analysis on pain chronicization suffers from a high rate of loss to follow up.

In conclusion, we describe here an evidence-based protocol for pain management in living related donor undergoing hepatectomy for liver transplantation. This protocol, based on nine measures, techniques and medications is feasible and has been proposed, but not uniformly applied in a series of hundred living liver donors. Taken together, these results show that proposing a protocol based on the most effective therapeutic measures is not sufficient to consider postoperative pain hepatectomy for living donation a resolved issue.

\section{Additional file}

Additional file 1. Postoperative complications, graded according to Dindo-Clavien classification in hundred living donors.

\section{Authors' contributions}

GD, AS, FL, RR, MDK and PF were involved in study concept and design; GD in acquisition of data; GD, AS and PF analyzed the data; all the authors participated in the interpretation of data and the preparation of the manuscript. All authors read and approved the final manuscript.

\section{Author details}

${ }^{1}$ Department of Anesthesiology, Cliniques Universitaires Saint-Luc, Avenue Hippocrate 10, 1200 Brussels, Belgium. ${ }^{2}$ Department of Anesthesiology,
Centre Hospitalier de Wallonie Picarde, Avenue Delmée 9, 7500 Tournai, Belgium. ${ }^{3}$ Department of Anesthesiology, Centre Hospitalier Universitaire du Sart-Tilman, Liège, Belgium. ${ }^{4}$ Department of Surgery and Transplantation, Cliniques Universitaires Saint Luc, Avenue Hippocrate 10, 1200 Brussels, Belgium. ${ }^{5}$ Department of Anesthesiology and Perioperative Medicine, Vrije Universiteit Brussel (VUB), Universitair Ziekenhuis Brussel (UZ Brussel), Laarbeeklaan 101, 1090 Brussels, Belgium.

\section{Acknowledgements}

The authors acknowledge all the colleagues from the PostOperative Pain Service.

\section{Competing interests}

The authors declare that they have no competing interests.

Availability of data and materials

All the data has been included in the tables.

Consent to publish

Not applicable.

Ethics approval and consent to participate

Ethics committee approval (Number 017/02JAN/003), Chairperson: Jean-Marie Maloteaux).

\section{Funding}

No external source of funding.

\section{Publisher's Note}

Springer Nature remains neutral with regard to jurisdictional claims in published maps and institutional affiliations.

Received: 12 September 2018 Accepted: 21 November 2018

Published online: 26 November 2018

\section{References}

1. Diaz GC, Renz JF, Mudge C, Roberts JP, Ascher NL, Emond JC, et al. Donor health assessment after living-donor liver transplantation. Ann Surg. 2002;236:120-6.

2. Holtzman S, Clarke HA, McCluskey SA, Turcotte K, Grant D, Katz J. Acute and chronic postsurgical pain after living liver donation: incidence and predictors. Liver Transplant. 2014;20:1336-46.

3. Bonnet A, Lavand'homme P, France MN, Reding R, De Kock M. Postoperative pain trajectories to identify risk of chronic postsurgical pain in living donors for liver transplantation. Ann Fr Anesth Reanim. 2012;31:945-9.

4. American Society of Anesthesiologists Task Force on Acute Pain M. Practice guidelines for acute pain management in the perioperative setting: an updated report by the American Society of Anesthesiologists Task Force on Acute Pain Management. Anesthesiology. 2012;116:248-73.

5. Ready LB. Acute perioperative pain. In: Cucchiara RF, Miller ED Jr, Reves JG, Roizen MF, Savarese JJ, editors. Anesthesia. 5th ed. New York: Churchill Livingstone; 2000. p. 2323-50.

6. James JD. Acute postoperative pain. In: Thomas H, Knight PR, editors. Wylie's textbook of anaesthesia. 7th ed. Edinburgh: Churchill Livingstone; 2003. p. 1213-34

7. Haller G, Stoelwinder J, Myles PS, McNeil J. Quality and safety indicators in anesthesia: a systematic review. Anesthesiology. 2009;110:1158-75.

8. Group OLoEW. The Oxford levels of evidence 2. Oxford Centre for Evidence-Based Medicine ed.

9. Egbert LD, Battit GE, Welch CE, Bartlett MK. Reduction of post operative pain by encouragement and instruction of patients: a study of doctorpatient rapport. N Engl J Med. 1964;270:825-7.

10. Deumens R, Steyaert A, Forget $P$, Schubert M, Lavand'homme P, Hermans $E$, et al. Prevention of chronic postoperative pain: cellular, molecular, and clinical insights for mechanism-based treatment approaches. Prog Neurobiol. 2013;104:1-37. 
11. Clarke H, Bonin RP, Orser BA, Englesakis M, Wijeysundera DN, Katz J. The prevention of chronic postsurgical pain using gabapentin and pregabalin: a combined systematic review and meta-analysis. Anesth Analg 2012;115:428-42.

12. Agarwal A, Gautam S, Gupta D, Agarwal S, Singh PK, Singh U. Evaluation of a single preoperative dose of pregabalin for attenuation of postoperative pain after laparoscopic cholecystectomy. Br J Anaesth. 2008;101:700-4.

13. Mishriky BM, Waldron NH, Habib AS. Impact of pregabalin on acute and persistent postoperative pain: a systematic review and meta-analysis. Br J Anaesth. 2015;114:10-31.

14. Buvanendran A, Kroin JS, Kari M, Tuman KJ. Can a single dose of $300 \mathrm{mg}$ of pregabalin reach acute antihyperalgesic levels in the central nervous system? Reg Anesth Pain Med. 2010;35:535-8.

15. Hindmarch I, Dawson J, Stanley N. A double-blind study in healthy volunteers to assess the effects on sleep of pregabalin compared with alprazolam and placebo. Sleep. 2005;28:187-93.

16. Hays RD, Martin SA, Sesti AM, Spritzer KL. Psychometric properties of the medical outcomes study sleep measure. Sleep Med. 2005;6:41-4.

17. Ben-Menachem E. Pregabalin pharmacology and its relevance to clinical practice. Epilepsia. 2004;45:13-8.

18. Bockbrader HN, Radulovic LL, Posvar EL, Strand JC, Alvey CW, Busch JA, et al. Clinical pharmacokinetics of pregabalin in healthy volunteers. J Clin Pharmacol. 2010;50:941-50.

19. Dahmani S, Brasher C, Stany I, Golmard J, Skhiri A, Bruneau B, et al. Premedication with clonidine is superior to benzodiazepines. A meta analysis of published studies. Acta Anaesthesiol Scand. 2010;54:397-402.

20. Blaudszun G, Lysakowski C, Elia N, Tramer MR. Effect of perioperative systemic alpha2 agonists on postoperative morphine consumption and pain intensity: systematic review and meta-analysis of randomized controlled trials. Anesthesiology. 2012;116:1312-22.

21. Quintin L, Bouilloc X, Butin E, Bayon MC, Brudon JR, Levron JC, et al. Clonidine for major vascular surgery in hypertensive patients: a double-blind, controlled, randomized study. Anesth Analg. 1996;83:687-95.

22. Nishina K, Mikawa K, Uesugi T, Obara H, Maekawa M, Kamae I, et al. Efficacy of clonidine for prevention of perioperative myocardial ischemia: a critical appraisal and meta-analysis of the literature. Anesthesiology. 2002;96:323-9.

23. Wijeysundera DN, Bender JS, Beattie WS. Alpha-2 adrenergic agonists for the prevention of cardiac complications among patients undergoing surgery. Cochrane Database Syst Rev. 2009. https://doi.org/10.1002/14651 858.CD004126.pub2.

24. Kumar G, Stendall C, Mistry R, Gurusamy K, Walker D. A comparison of total intravenous anaesthesia using propofol with sevoflurane or desflurane in ambulatory surgery: systematic review and meta-analysis. Anaesthesia. 2014;69:1138-50.

25. Sneyd JR, Carr A, Byrom WD, Bilski AJ. A meta-analysis of nausea and vomiting following maintenance of anaesthesia with propofol or inhalational agents. Eur J Anaesthesiol. 1998;15:433-45.

26. Nakanuno R, Yasuda T, Hamada H, Yoshikawa H, Nakamura R, Saeki N, et al. Propofol for anesthesia and postoperative sedation resulted in fewer inflammatory responses than sevoflurane anesthesia and midazolam sedation after thoracoabdominal esophagectomy. Hiroshima J Med Sci. 2015;64:31-7.

27. Nie Y, LU YX, LV LH. Effect of propofol on generation of inflammatory mediator of monocytes. Asian Pac J Trop Med. 2015;8:964-70.

28. Qiao Y, Feng H, Zhao T, Yan H, Zhang H, Zhao X. Postoperative cognitive dysfunction after inhalational anesthesia in elderly patients undergoing major surgery: the influence of anesthetic technique, cerebral injury and systemic inflammation. BMC Anesthesiol. 2015;15:154.

29. Zhou CH, Zhu YZ, Zhao PP, Xu CM, Zhang MX, Huang H, et al. Propofol inhibits lipopolysaccharide-induced inflammatory responses in spinal astrocytes via the toll-like receptor 4/MyD88-dependent nuclear factorkappaB, extracellular signal-regulated protein kinases 1/2, and p38 mitogen-activated protein kinase pathways. Anesth Analg. 2015;120:1361-8.

30. Li J, Kandatsu N, Feng GG, Jiang JZ, Huang L, Kinoshita $H$, et al. Propofol reduces liver dysfunction caused by tumor necrosis factor-alpha production in Kupffer cells. J Anesth. 2016;30(3):420-6.

31. Li M, Mei W, Wang P, Yu Y, Qian W, Zhang ZG, et al. Propofol reduces early post-operative pain after gynecological laparoscopy. Acta Anaesthesiol Scand. 2012;56:368-75.
32. Célèrier PDE, Rivat BSC, Jun MDY, Laulin PDJ-P, Larcher PDA, Reynier MDP, et al. Long-lasting hyperalgesia induced by fentanyl in rats preventive effect of ketamine. Anesthesiology. 2000;92:465-.

33. Marion Lee M, Sanford Silverman M, Hans Hansen M, Vikram Patel M. A comprehensive review of opioid-induced hyperalgesia. Pain Physician. 2011;14:145-61.

34. Aubrun F, Valade N, Coriat P, Riou B. Predictive factors of severe postoperative pain in the postanesthesia care unit. Anesth Analg. 2008;106:1535-41.

35. Guignard B, Bossard AE, Coste C, Sessler DI, Lebrault C, Alfonsi P, et al. Acute opioid tolerance: intraoperative remifentanil increases postoperative pain and morphine requirement. Anesthesiology. 2000;93:409-17.

36. Bakan M, Umutoglu T, Topuz U, Uysal H, Bayram M, Kadioglu H, et al. Opioid-free total intravenous anesthesia with propofol, dexmedetomidine and lidocaine infusions for laparoscopic cholecystectomy: a prospective, randomized, double-blinded study. Braz J Anesthesiol. 2015;65:191-9.

37. Ziemann-Gimmel P, Goldfarb AA, Koppman J, Marema RT. Opioidfree total intravenous anaesthesia reduces postoperative nausea and vomiting in bariatric surgery beyond triple prophylaxis. $\mathrm{Br} J$ Anaesth. 2014;112:906-11.

38. ParkWY, Thompson JS, Lee KK. Effect of epidural anesthesia and analgesia on perioperative outcome: a randomized, controlled veterans affairs cooperative study. Ann Surg. 2001;234:560-9 (discussion 9-71).

39. Behera BK, Puri GD, Ghai B. Patient-controlled epidural analgesia with fentanyl and bupivacaine provides better analgesia than intravenous morphine patient-controlled analgesia for early thoracotomy pain. J Postgrad Med. 2008;54:86-90.

40. Lavand'homme P, De Kock M, Waterloos H. Intraoperative epidural analgesia combined with ketamine provides effective preventive analgesia in patients undergoing major digestive surgery. Anesthesiology. 2005;103:813-20.

41. Clarke H, Chandy T, Srinivas C, Ladak S, Okubo N, Mitsakakis N, et al. Epidural analgesia provides better pain management after live liver donation: a retrospective study. Liver Transplant. 2011;17:315-23.

42. Rodgers A, Walker N, Schug S, McKee A, Kehlet H, van Zundert A, et al. Reduction of postoperative mortality and morbidity with epidural or spinal anaesthesia: results from overview of randomised trials. BMJ. 2000;321:1493.

43. Rigg JR, Jamrozik K, Myles PS, Silbert BS, Peyton PJ, Parsons RW, et al. Epidural anaesthesia and analgesia and outcome of major surgery: a randomised trial. Lancet (London, England). 2002;359:1276-82.

44. Popping DM, Elia N, Marret E, Remy C, Tramer MR. Protective effects of epidural analgesia on pulmonary complications after abdominal and thoracic surgery: a meta-analysis. Arch Surg (Chicago, III: 1960). 2008;143:990-9 (discussion 1000).

45. Wijeysundera DN, Beattie WS, Austin PC, Hux JE, Laupacis A. Epidural anaesthesia and survival after intermediate-to-high risk non-cardiac surgery: a population-based cohort study. Lancet (London, England). 2008;372:562-9.

46. Guay J, Choi PT, Suresh S, Albert N, Kopp S, Pace NL. Neuraxial anesthesia for the prevention of postoperative mortality and major morbidity: an overview of cochrane systematic reviews. Anesth Analg. 2014;119:716-25.

47. Ballantyne JC, Kupelnick B, McPeek B, Lau J. Does the evidence support the use of spinal and epidural anesthesia for surgery? J Clin Anesth. 2005;17:382-91.

48. Kuo CP, Jao SW, Chen KM, Wong CS, Yeh CC, Sheen MJ, et al. Comparison of the effects of thoracic epidural analgesia and i.v. infusion with lidocaine on cytokine response, postoperative pain and bowel function in patients undergoing colonic surgery. Br J Anaesth. 2006;97:640-6.

49. Weibel S, Jokinen J, Pace NL, Schnabel A, Hollmann MW, Hahnenkamp K, et al. Efficacy and safety of intravenous lidocaine for postoperative analgesia and recovery after surgery: a systematic review with trial sequential analysis. Br J Anaesth. 2016;116:770-83.

50. Loix S, De Kock M, Henin P. The anti-inflammatory effects of ketamine: state of the art. Acta Anaesthesiol Belg. 2011;62:47-58.

51. Bell RF, Dahl JB, Moore RA, Kalso E. Perioperative ketamine for acute postoperative pain. Cochrane Database Syst Rev. 2006;1:Cd004603.

52. Elia N, Tramer MR. Ketamine and postoperative pain-a quantitative systematic review of randomised trials. Pain. 2005;113:61-70. 
53. Laskowski K, Stirling A, McKay WP, Lim HJ. A systematic review of intravenous ketamine for postoperative analgesia. Can J Anesth. 2011;58:911-23.

54. De Kock M, Lavand'homme P, Waterloos H. 'Balanced analgesia' in the perioperative period: is there a place for ketamine? Pain. 2001;92:373-80.

55. Albrecht E, Kirkham KR, Liu SS, Brull R. Peri-operative intravenous administration of magnesium sulphate and postoperative pain: a meta-analysis. Anaesthesia. 2013;68:79-90.

56. De Oliveira GS Jr, Castro-Alves LJ, Khan JH, McCarthy RJ. Perioperative systemic magnesium to minimize postoperative pain: a meta-analysis of randomized controlled trials. Anesthesiology. 2013;119:178-90.

57. Cataldo PA, Senagore AJ, Kilbride MJ. Ketorolac and patient controlled analgesia in the treatment of postoperative pain. Surg Gynecol Obstet. 1993;176:435-8

58. Sevarino FB, Sinatra RS, Paige D, Silverman DG. Intravenous ketorolac as an adjunct to patient-controlled analgesia (PCA) for management of postgynecologic surgical pain. J Clin Anesth. 1994;6:23-7.

59. Vetter TR, Heiner EJ. Intravenous ketorolac as an adjuvant to pediatric patient-controlled analgesia with morphine. J Clin Anesth. 1994;6:1 10-3.

60. Nozadze I, Tsiklauri N, Gurtskaia G, Tsagareli MG. NSAIDs attenuate hyperalgesia induced by TRP channel activation. Data Brief. 2016;6:668-73.

61. De Oliveira Jr GS, Agarwal D, Benzon HT. Perioperative single dose ketorolac to prevent postoperative pain: a meta-analysis of randomized trials. Anesth Analg. 2012;114:424-33.

62. Gobble RM, Hoang HL, Kachniarz B, Orgill DP. Ketorolac does not increase perioperative bleeding: a meta-analysis of randomized controlled trials. Plast Reconstr Surg. 2014;133:741-55.

63. Rao W, Zhang X, Zhang J, Yan R, Hu Z, Wang Q. The role of nasogastric tube in decompression after elective colon and rectum surgery: a metaanalysis. Int J Colorectal Dis. 2011;26:423-9.
64. Hamerlynck JV, Middeldorp S. From the Cochrane Library: routine use of nasogastric tubes after abdominal surgery is not effective. Ned Tijdschr Geneeskd. 2005;149:2279-80.

65. Nelson R, Tse B, Edwards S. Systematic review of prophylactic nasogastric decompression after abdominal operations. Br J Surg. 2005;92:673-80.

66. Mackintosh C, Bowles S. Evaluation of a nurse-led acute pain service. Can clinical nurse specialists make a difference? J Adv Nurs. 1997:25:30-7.

67. Miaskowski C, Crews J, Ready LB, Paul SM, Ginsberg B. Anesthesia-based pain services improve the quality of postoperative pain management. Pain. 1999;80:23-9.

68. Bardiau FM, Taviaux NF, Albert A, Boogaerts JG, Stadler M. An intervention study to enhance postoperative pain management. Anesth Analg. 2003:96:179-85 (table of contents).

69. Stadler M, Schlander M, Braeckman M, Nguyen T, Boogaerts JG. A costutility and cost-effectiveness analysis of an acute pain service. J Clin Anesth. 2004;16:159-67.

70. Gerbershagen HJ, Rothaug J, Kalkman CJ, Meissner W. Determination of moderate-to-severe postoperative pain on the numeric rating scale: a cut-off point analysis applying four different methods. Br J Anaesth. 2011;107:619-26.

71. Aubrun F, Langeron O, Quesnel C, Coriat P, Riou B. Relationships between measurement of pain using visual analog score and morphine requirements during postoperative intravenous morphine titration. Anesthesiology. 2003;98:1415-21.

72. Dindo D, Demartines N, Clavien PA. Classification of surgical complications: a new proposal with evaluation in a cohort of 6336 patients and results of a survey. Ann Surg. 2004;240:205-13.
Ready to submit your research? Choose BMC and benefit from:

- fast, convenient online submission

- thorough peer review by experienced researchers in your field

- rapid publication on acceptance

- support for research data, including large and complex data types

- gold Open Access which fosters wider collaboration and increased citations

- maximum visibility for your research: over 100M website views per year

At BMC, research is always in progress.

Learn more biomedcentral.com/submissions 